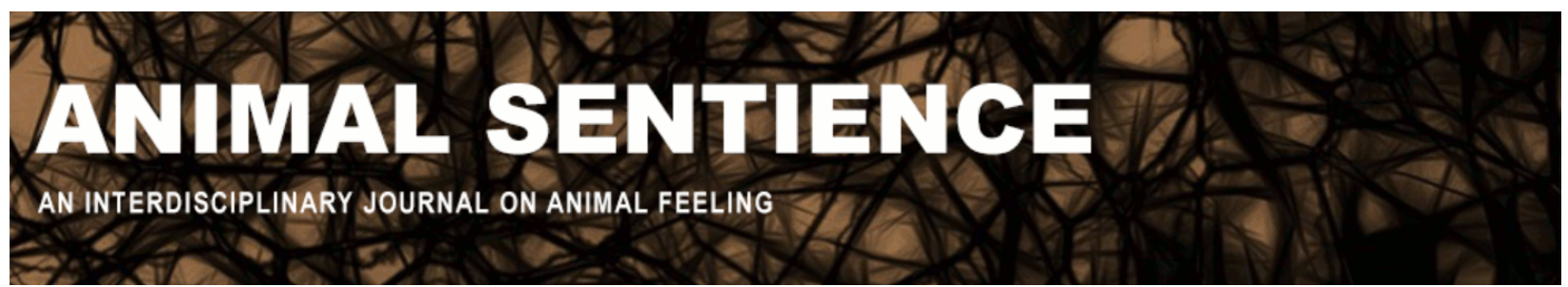

Gagliano, Monica (2016) What would the Babel fish say?. Animal Sentience 3(20) DOI: $10.51291 / 2377-7478.1044$

Date of submission: $2015-10-20$

Date of acceptance: 2015-12-13

(c) (i)




\title{
What would the Babel fish say?
}

Commentary on Key on Fish Pain

\author{
Monica Gagliano \\ School of Animal Biology \\ University of Western Australia
}

\begin{abstract}
Starting with its title, Key's (2016) target article advocates the view that fish do not feel pain. The author describes the neuroanatomical, physiological and behavioural conditions involved in the experience of pain in humans and rodents and confidently applies analogical arguments as though they were established facts in support of the negative conclusion about the inability of fish to feel pain. The logical reasoning, unfortunately, becomes somewhat incoherent, with the arbitrary application of the designated human criteria for an analogical argument to one animal species (e.g., rodents) but not another (fish). Research findings are reported selectively, and questionable interpretations are invoked to support the author's position. In this commentary, I briefly examine two of the analogies presented in Key's target article and highlight the role (and consequences) that personal opinions and preconceptions have in issues concerning human ethical responsibilities toward the welfare of non-human species.
\end{abstract}

Keywords: pain, fish, consciousness, feeling, sentience, ethics, analogies

\begin{abstract}
Monica Gagliano monica.gagliano@uwa.edu.au is Research Associate Professor of Evolutionary Ecology and Research Fellow of the Australian Research Council at the University of Western Australia. She has written many articles on animal and plant behavioural and evolutionary ecology. She pioneered the new research field of plant bioacoustics and recently extended the concept of cognition to plants, reigniting the discourse on plant subjectivity and ethical standing. http://www.uwa.edu.au/people/monica.gagliano

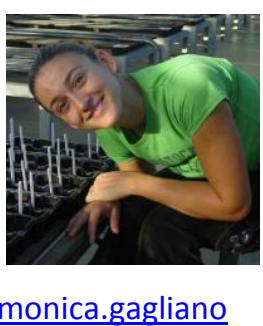

Introduction. The appeal of thinking by analogy rests in the fact that it allows us to explain complicated ideas in an accessible way by creating mental pictures that relate the new and unfamiliar to what we already know. However, the danger of argument by analogy is widely recognised. Whether in politics, science or other areas of human thought, such arguments are only as good as the premises that support them. In his target article, Key (2016) uses a series of analogical arguments to tackle the contentious issue of whether fish feel pain, confidently concluding that they do not. Like other authors before him (e.g., Rose, 2002; Arlinghaus, Cooke, Schwab, \& Cowx, 2007), Key argues that fish are not capable of feeling pain (or, more generally, of suffering) because they lack the necessary neuroanatomy and physiology underlying such feelings in humans. His line of reasoning is clearly self-consistent: but are the original premises valid, and do they support his conclusion?

As pointed out by Cottee (2012) in her discussion of fear, pain and animal consciousness, argument-by-analogy is a widely used method of comparing animal responses to specific experiences with those of humans (and sometimes with those of the few 'higher' animal species that are generally considered as having consciousness). When it comes to the 
specific question of fish and whether they have the capacity to experience mental states such as pain and fear, this longstanding practice of analogical reasoning is used both by those who do and those who do not believe fish can suffer. Though powerful, argument-byanalogy can become problematic (1) when it inappropriately considers human beings to be the most important species in nature and hence uses human traits as the reference point against which non-human experiences are measured (i.e. anthropocentrism), or (2) when it attributes human-like behaviours, mental states and emotions to non-human others (i.e. anthropomorphism). Anthropocentrism is generally considered valid and necessary (Murdy, 1975), though it sometimes arbitrarily favours organisms that are more like us (Andrews, 2015). Anthropomorphism is usually seen as a source of error to be avoided, yet one that can sometimes help us better predict and explain those behaviours (Horowitz \& Bekoff, 2007). In my view, what matters is whether the analogies we use provide a clearer understanding and appreciation of nature or lead us down the road of biased arguments and false beliefs.

Anthropocentric analogy. In humans, the cortex is the brain region responsible for pain perception; hence, as the human yardstick for assessing pain, cortical activity may be a valid indicator of the presence of pain in those animals (e.g., rodents) that have a cortex. It does not follow from this, however, that the lack of a cortex is a valid indicator of the absence of pain (e.g., Rose, 2002; Rose et al., 2014; and Key, 2016). This fallacy has been pointed out time and time again (e.g., Chandroo, Yue \& Moccia, 2004; Braithwaite \& Boulcott, 2007; Sneddon 2012; Cottee 2012; Segner 2012; Andrews 2015; Brown 2015). Invalid arguments by analogy from structure (e.g., a particular neural network) to its necessity for function (e.g., learning and memory) occur in various areas of biological research. The critical peer commentary on Key's target article accordingly provides a useful warning of the pitfalls of this line of reasoning.

Anthropomorphic analogy. We can test whether animals react to what humans would perceive as painful stimuli with behaviours similar to those generally exhibited by humans. For example, since post-craniotomy pain in humans typically restricts physical movement and reduces social function, similar effects in animals (e.g., craniotomy in rodents) would (as suggested by Key) be indicative of pain. Experimental studies have indeed evaluated these behavioural criteria following craniotomy in fish (Davis, Kassel \& Schwagmeyer, 1976; Kassel, Davis \& Schwagmeyer, 1976; Schwagmeyer, Davis \& Kassel, 1977; Davis, Reynolds \& Ricks, 1978). The experimental evidence from these studies (although misreported by Key) indicates that craniotomy in fish does affect normal physical movement such as swimming as well as a range of socio-behavioural activities including courtship, building and tending nests, and other reproductive behaviours. Hence if we apply Key's analogy, then fish, like rodents and humans, do feel pain. This conclusion then agrees with the compelling and extensive published evidence of pain in fish that was oddly omitted from Key's target article (e.g., as reviewed by Braithwaite, 2010; Sneddon, 2011; Cottee, 2012; Segner, 2012; Brown, 2015; and numerous others). Ironically given Key's criticism of anthropomorphic tendencies, it is his own anthropomorphic analogy (when applied correctly) that - unlike his anthropocentric argument - seems to do the job of answering the question of whether fish feel pain.

Of Babel fish and red herrings. In Adams's The Hitchhiker's Guide to the Galaxy, we are introduced to a fictional alien fish that can cross the language barrier between species to 
perform instant translations (Adams, 1980). The Babel fish, as it is known, is probably the only fish species ever able to use human language and report on 'what it feels like' for a fish to be injured and in pain. However, do we really need a Babel fish to resolve the controversy about pain and suffering in fish? Through careful experimental analysis, fish have been allowed to display a number of physiological as well as behavioural responses to inform the human observer of their cognitive and emotional states, including pain (see reviews by Braithwaite, 2010; Sneddon, 2011; Cottee, 2012; Segner, 2012; Brown, 2015; and references therein). The available experimental evidence is indeed quite clear on the issue. Therefore, we need no more 'red herrings' to engage us in a discussion of personal beliefs and biased interpretations of scientific evidence instead of addressing the real issue concerning the welfare of the animal.

\section{References}

Adams, D. (1980). The hitchhiker's guide to the galaxy. New York, NY: Harmony Books.

Andrews, K. (2015). The animal mind. An introduction to the philosophy of animal cognition. New York, NY: Routledge.

Arlinghaus, R., Cooke, S. J., Schwab, A. \& Cowx, I. G. (2007). Fish welfare: a challenge to the feelings-based approach, with implications for recreational fishing. Fish and Fisheries, 8, 57-71. doi:10.1111/j.1467-2979.2007.00233.x

Braithwaite, V. A. (2010). Do fish feel pain? New York, NY: Oxford University Press.

Braithwaite, V. A. \& Boulcott, P. (2007). Pain perception, aversion and fear in fish. Diseases of Aquatic Organisms, 75, 131-138. doi:10.3354/dao075131

Brown, C. (2015). Fish intelligence, sentience and ethics. Animal Cognition, 18, 1-17. doi:10.1007/s10071-014-0761-0

Chandroo, K. P., Yue, S. \& Moccia, R. D. (2004). An evaluation of current perspectives on consciousness and pain in fishes. Fish and Fisheries, 5, 281-295. doi:10.1111/j.14672679.2004.00163.x

Cottee, S. Y. (2012). Are fish victims of "speciesism"? A discussion about fear, pain and animal consciousness. Fish Physiology and Biochemistry, 38, 5-15. doi:10.1007/s10695010-9449-9

Davis, R. E., Kassel, J. \& Schwagmeyer, P. (1976). Telencephalic lesions and behavior in the teleost, Macropodus opercularis: reproductive, startle reaction, and operant behavior in the male. Behavioral Biology, 18, 165-177. doi:10.1016/S0091-6773(76)92054-X

Davis, R. E., Reynolds, R. C. \& Ricks, A. (1978). Suppression behaviour increased by telencephalic lesions in the teleost, Macropodus opercularis. Behavioral Biology, 24, 3248. doi:10.1016/S0091-6773(78)92866-3 
Horowitz, A. C. \& Bekoff, M. (2007). Naturalizing anthropomorphism: behavioural prompts to our humanizing of animals. Journal of the Interactions of People \& Animals, 20, 23-35.

Kassel, J., Davis, R. E. \& Schwagmeyer, P. (1976). Telencephalic lesions and behavior in the teleost, Macropodus opercularis: further analysis of reproductive and operant behavior in the male. Behavioral Biology, 18, 178-179. doi:10.1016/S0091-6773(76)92070-8

Key, B. (2016). Why fish do not feel pain. Animal Sentience 2016.003.

Murdy, W. H. (1975). Anthropocentrism: a modern version. Science, 187, 1168-1172. doi:10.1126/science.187.4182.1168

Rose, J. D. (2002). The neurobehavioural nature of fishes and the question of awareness and pain. Reviews in Fisheries Science, 10, 1-38. doi:10.1080/20026491051668

Rose, J. D., Arlinghaus, R., Cooke, S. J., Diggles, B. K., Sawynok, W., Stevens, E. D. \&

Wynne, C. D. L. (2014). Can fish really feel pain? Fish and Fisheries, 15, 97-133. doi:10.1111/faf.12010

Schwagmeyer, P., Davis, R. E. \& Kassel, J. (1977). Telencephalic lesions and behaviour in the teleost Macropodus opercularis (L.): effects of telencephalon and olfactory bulb ablation on spawning and foamnest building. Behavioral Biology, 20, 463-470. doi:10.1016/S00916773(77)91060-4

Segner, H. (2012). Fish. Nociception and pain - a biological perspective. In Federal Committee on Non-Human Biotechnology ECNH \& A. Willemsen (Eds.), Contributions to Ethics and Biotechnology (Vol. 9). Bern: Federal Office for Buildings and Logistics (FOBL). doi.org/10.7892/boris.41321

Sneddon, L. U. (2011). Pain perception in fish: evidence and implications for the use of fish. Journal of Consciousness Studies, 18, 209-229.

Sneddon, L. U. (2012). Pain perception in fish: why critics cannot accept the scientific evidence for fish pain? https://www.liv.ac.uk/media/livacuk/iib/fish/Response to Rose 2012.pdf 